\title{
Differential effects of fatness, fitness and physical activity energy expenditure on whole-body, liver and fat insulin sensitivity
}

\author{
H. B. Holt • S. H. Wild • N. Wareham • U. Ekelund • \\ M. Umpleby • F. Shojaee-Moradie • R. I. G. Holt • \\ D. I. Phillips • C. D. Byrne
}

Received: 8 February 2007 / Accepted: 17 April 2007 / Published online: 30 May 2007

(C) Springer-Verlag 2007

\begin{abstract}
Aims/hypothesis The relative contributions of fitness (maximal oxygen uptake), physical activity energy expenditure (PAEE) and fatness to whole-body, liver and fat insulin sensitivity is uncertain. The aim of this study was to determine whether fitness and PAEE are associated with whole-body, liver and fat insulin sensitivity independently of body fat.

Materials and methods We recruited 25 men (mean [SD] age 53 [6] years). Whole-body ( $M$ value) and liver (percentage suppression of endogenous glucose output)
\end{abstract}

H. B. Holt • R. I. G. Holt • C. D. Byrne

Endocrinology and Metabolism, DOHaD Division,

School of Medicine, University of Southampton,

Southampton, UK

\section{S. H. Wild}

Public Health Sciences, University of Edinburgh,

Edinburgh, UK

N. Wareham $\cdot$ U. Ekelund

MRC Epidemiology Unit,

Cambridge, UK

M. Umpleby • F. Shojaee-Moradie

Wolfson Centre for Translational Research,

Diabetes and Endocrinology, University of Surrey,

Guildford, UK

\section{I. Phillips}

MRC Resource Centre,

Southampton, UK

C. D. Byrne $(\square)$

Endocrinology and Metabolism, Mail point 113, Level F,

Centre Block, Southampton General Hospital,

Tremona Road,

Southampton SO16 6YD, UK

e-mail: C.D.Byrne@soton.ac.uk insulin sensitivity were estimated using a hyperinsulinaemic-euglycaemic clamp. Insulin sensitivity in fat (insulin sensitivity index for NEFA) was estimated during an OGTT. Total and truncal fat were measured by dual-energy X-ray absorptiometry, fitness by treadmill, and PAEE $(n=21)$ by 3 day heart rate monitoring and Baecke questionnaire.

Results In univariate analyses, fatness was strongly associated with insulin sensitivity (whole-body, liver and fat). Fitness was associated with whole-body $(r=0.53, p<0.007)$ and liver $(0.42, p=0.04)$ insulin sensitivity, while PAEE was associated with liver insulin sensitivity $(r=0.55, p=0.01)$. Regression models were established to describe associations between fatness, fitness and physical activity and measures of insulin sensitivity (whole-body, fat and liver) as outcomes. Only fatness was independently associated with whole-body insulin sensitivity ( $B$ coefficient $-0.01, p=0.001$ ). Fitness was not associated with any outcome. Only PAEE was independently associated with liver insulin sensitivity ( $B$ coefficient 13.5, $p=0.02$ ).

Conclusions/interpretation Fatness explains most of the variance in whole-body insulin sensitivity. In contrast, PAEE explains most of the variance in liver insulin sensitivity.

Keywords Fitness · Hyperinsulinaemic-euglycaemic clamp · Insulin resistance $\cdot$ Insulin sensitivity (whole-body, liver and fat) - Obesity (visceral, truncal and subcutaneous) - PAEE . Physical activity. Physical activity energy expenditure

\author{
Abbreviations \\ HOMA-IR homeostasis model assessment \\ for insulin resistance \\ ISI insulin sensitivity index \\ PAEE physical activity energy expenditure
}


$R_{\mathrm{a}} \quad$ rate of appearance of glucose

$R_{\mathrm{d}} \quad$ rate of disappearance of glucose

TTR tracer to tracee ratio

$V \mathrm{O}_{2}$ peak maximal oxygen uptake

\section{Introduction}

High levels of fitness and physical activity are associated with a lower prevalence of insulin resistance [1-3] and metabolic syndrome [4, 5]. It has been suggested that fitness and/or physical activity may be more important than body fatness in determining whole-body insulin resistance and metabolic syndrome [6-8]. Fitness and physical activity are often negatively related to body fatness and both fitness and physical activity attenuate metabolic risk independently of their effect on body fatness $[9,10]$.

Exercise improves insulin-mediated glucose uptake in muscle [11] via increasing expression of GLUT4 on muscle cell membranes (an insulin-dependent mechanism) [12]. Although the increase in whole-body insulin sensitivity is dependent on the relative intensity and duration of the exercise [13], the impact of low levels of physical activity on insulin sensitivity in individual tissues, such as liver and fat, is uncertain. Exercise without weight loss results in an improvement in whole-body insulin sensitivity. However, it is uncertain whether any improvements in insulin sensitivity that are associated with exercise occur because of exercise-induced changes in body composition [14] or because of a benefit, induced by physical activity, in tissue insulin sensitivity.

The terms physical activity and fitness are sometimes used interchangeably when considering the impact of training and habitual exercise on body composition and cardiovascular risk factors. However, it is important to differentiate between fitness and physical activity energy expenditure (PAEE). The latter is defined as the energy expenditure attributable to body movement, whereas fitness is an attribute influenced by genes and exercise (a subcomponent of physical activity). It is therefore necessary to consider fitness and PAEE separately [15] in studies of insulin sensitivity and body fatness.

The Diabetes Prevention Program demonstrated that intensive lifestyle modification reduced the risk of diabetes by an impressive 58\% [16]. The Diabetes Prevention Program intervention included four aims: $>7 \%$ weight loss; reduction in dietary fat intake to $<25 \%$ of energy intake; reduction of total energy intake to $5,040-7,560 \mathrm{~kJ} / \mathrm{day}$; and an increase in physical activity to $>150 \mathrm{~min} /$ week. From a practical point of view, it would useful to know whether each of these interventions has equal importance in diabetes prevention. In a further analysis of the Diabetes Prevention Program data using Cox proportional hazards regression, weight loss was found to be the dominant predictor of reduced diabetes incidence [17]. For every kilogram of weight loss, there was a $16 \%$ reduction in risk after adjustment for changes in diet and activity. Although decreased fat intake and increased physical activity predicted weight loss, increased physical activity as such was important to help sustain weight loss.

Although these findings suggest that interventions to reduce diabetes risk should primarily target weight reduction, the other aspects of lifestyle should not be ignored. Among those who were unable to achieve the weight loss goal, achieving the physical activity goal lowered the risk of diabetes by $44 \%$. To date it is not known whether there is an independent effect of fitness and PAEE on individual tissue insulin sensitivity, having taken account of body fatness. We hypothesised that the effect of PAEE and fitness on individual insulin sensitivity is independent of body fatness. The aim of this study, therefore, was to determine whether fatness (total or truncal), fitness and PAEE are independently associated with individual tissue insulin sensitivity (whole-body, fat and liver) in men.

\section{Materials and methods}

Subjects Twenty-five healthy male volunteers aged 42 64 years with a wide range of BMIs (Table 1) participated in the study. Cardiorespiratory fitness was determined after volunteers had avoided strenuous exercise for $24 \mathrm{~h}$ and fasted for $8 \mathrm{~h}$. Physical activity was assessed by wearing a heart rate monitor for 3 days and individual calibration using the treadmill or ergometer data, as well as by means of a Baecke questionnaire as described below. Tissue insulin sensitivity was measured using the hyperinsulinaemic-euglycaemic clamp with deuterated glucose and NEFA suppression during the OGTT (see below). Participants provided informed consent and the study was approved by the Southampton University Hospitals Trust Local Research Ethics Committee.

Body composition and metabolic syndrome features Homeostasis model assessment for insulin resistance (HOMAIR) was calculated from fasting plasma samples and an OGTT was performed with a $75 \mathrm{~g}$ glucose load. Plasma glucose was measured on fluoride samples by the glucose oxidase method using a YSI glucose analyser (Yellow Springs, OH, USA). Total cholesterol, HDL cholesterol and triacylglycerols were measured on fasting serum using in vitro enzymatic colorimetric kit methods according to the manufacturers' instructions (Advia 1650 Chemistry System; Bayer Diagnostics, Leverkusen, Germany).

Volunteers were weighed in light clothing to the nearest $0.1 \mathrm{~kg}$. Height was measured using a stadiometer to the 
Table 1 Baseline characteristics

\begin{tabular}{|c|c|c|}
\hline & Mean \pm SD & Range \\
\hline Age (years) & $52.6 \pm 5.5$ & $42.0-64.0$ \\
\hline $\operatorname{BMI}\left(\mathrm{kg} / \mathrm{m}^{2}\right)$ & $31.9 \pm 7.5$ & $20.8-48.9$ \\
\hline Total fat measured on DEXA (kg) & $28.8 \pm 14.0$ & $7.7-62.9$ \\
\hline Truncal fat on DEXA $(\mathrm{kg})$ & $15.4 \pm 8.5$ & $3.3-36.1$ \\
\hline Waist circumference $(\mathrm{cm})$ & $109 \pm 20$ & $80-150$ \\
\hline Hip circumference $(\mathrm{cm})$ & $114 \pm 12.9$ & $94-146$ \\
\hline Systolic BP (mmHg) & $129 \pm 10$ & $102-147$ \\
\hline Diastolic BP (mmHg) & $74 \pm 10$ & $58-83$ \\
\hline Fasting plasma glucose $(\mathrm{mmol} / \mathrm{l})$ & $5.4 \pm 0.5$ & $4.5-7.0$ \\
\hline Cholesterol $(\mathrm{mmol} / \mathrm{l})$ & $5.8 \pm 1.1$ & $3.7-7.8$ \\
\hline HDL cholesterol $(\mathrm{mmol} / \mathrm{l})$ & $1.38 \pm 0.45$ & $0.80-2.55$ \\
\hline Triacylglycerols $(\mathrm{mmol} / \mathrm{l})$ & $1.66 \pm 1.0$ & $0.70-4.90$ \\
\hline HOMA-IR & $0.50 \pm 0.42$ & $0.09-1.95$ \\
\hline Baseline insulin (pmol/l) & $14.3 \pm 10.9$ & $2.8-46.4$ \\
\hline Whole-body glucose disposal ${ }^{\mathrm{a}}$ & $7.0 \pm 3.5$ & $2.2-13.9$ \\
\hline $\begin{array}{l}\text { Suppression endogenous } \\
\text { glucose output }(\%)^{\mathrm{b}}\end{array}$ & $69.0 \pm 24.0$ & $24.4-100.0$ \\
\hline ISI NEFA ${ }^{\mathrm{c}}$ & $0.60 \pm 0.40$ & $0.13-1.60$ \\
\hline$V \mathrm{O}_{2}$ peak $\left(\mathrm{ml} \mathrm{min} \mathrm{mg}^{-1} \mathrm{~kg}^{-1}\right)$ & $29.0 \pm 9.0$ & $13.8-43.5$ \\
\hline $\operatorname{PAEE}\left(\mathrm{kJ} \mathrm{kg}^{-1} \text { day }^{-1}\right)^{\mathrm{d}}$ & $37.9 \pm 37.3$ & $1.89-167.6$ \\
\hline Baecke work score & $2.5 \pm 0.5$ & $1.3-4.1$ \\
\hline Baecke sport score & $2.8 \pm 1.0$ & $1.0-4.5$ \\
\hline Baecke leisure score & $3.1 \pm 0.5$ & $2.0-4.5$ \\
\hline Baecke total score & $8.4 \pm 1.5$ & $4.3-10.3$ \\
\hline
\end{tabular}

Group health status: IGT, three volunteers; diabetes, one volunteer diagnosed by OGTT testing, no specific treatment; never smokers, seven volunteers; current smokers, none; regular medications, one volunteer only (stable on thyroxine replacement therapy)

DEXA Dual-energy X-ray absorptiometry, HOMA homeostasis model ${ }^{a} M$ value, $\mathrm{mg} \mathrm{kg}^{-1} \mathrm{~min}^{-1}$, measure of whole-body insulin sensitivity

${ }^{\mathrm{b}}$ By 60 min insulin, measure of liver insulin sensitivity

${ }^{\mathrm{c}}$ Measure of fat insulin sensitivity

${ }^{\mathrm{d}} n=21$ volunteers (PAEE data not available on four men) assessment

nearest $0.1 \mathrm{~cm}$. BMI was calculated according to the formula (weight in $\mathrm{kg}) /\left([\text { height in metres }]^{2}\right)$.

Waist measurement was measured over bare skin midway between the costal margin and the iliac crest. Hip circumference was measured at the widest part between the greater trochanter and lower buttock level. Dual X-ray absorptiometry scanning was undertaken on a Delphi W instrument (Hologic, Bedford, MA, USA) and using a standard visual method to divide images into trunk, limb and head. Blood pressure was measured using a Marquette Dash 3000 monitor (GE Healthcare, Little Chalfont, Bucks, UK).

Fitness Cardiorespiratory fitness measured in terms of maximal oxygen uptake $\left(\mathrm{VO}_{2}\right.$ peak) was determined after volunteers had avoided strenuous exercise for $24 \mathrm{~h}$ and fasted for $8 \mathrm{~h}$. Volunteers were asked to avoid alcohol on the day prior to testing. On arrival at the Wellcome Trust Clinical Research Facility, volunteers were weighed and then asked to rest quietly for $30 \mathrm{~min}$ prior to testing. They were then fitted with an air-tight facemask, which allowed analysis of expired air, and with a heart rate monitor, ECG leads and blood pressure cuff. To allow volunteers to become acclimatised to the facemask and also to determine resting energy expenditure, resting measurements were taken for 20 min prior to commencement of measurements proper. Breath-by-breath analysis of oxygen consumption and $\mathrm{CO}_{2}$ production was made using a Cortex metalyser instrument (Cortex Biophysik, Germany) which was calibrated against gases of known concentration at the beginning of each day.

Volunteers were asked to perform an incremental treadmill test commencing at $1.3 \mathrm{~m} / \mathrm{s}(3 \mathrm{miles} / \mathrm{h})$ at a gradient of $0 \%$ and increasing alternately by $2 \%$ gradient or $0.25 \mathrm{~m} / \mathrm{s}(0.5 \mathrm{miles} / \mathrm{h}$ ) every $2 \mathrm{~min}$ (i.e. stage $1: 1.3 \mathrm{~m} / \mathrm{s}, 0 \%$ gradient; stage $2: 1.3 \mathrm{~m} / \mathrm{s}, 2 \%$ gradient; stage $3: 1.55 \mathrm{~m} / \mathrm{s}$, $2 \%$ gradient). The ECG was recorded throughout and blood pressure was measured intermittently. Volunteers were asked to continue to exhaustion unless they experienced chest pain or felt unwell. They were encouraged to continue until the respiratory exchange ratio was $>1.1$ and they had reached $90 \%$ of their predicted maximum heart rate (as determined by 220 -age). Three volunteers who were unable to run on the treadmill performed a cycle ergometer test instead, as follows: $\mathrm{VO}_{2}$ peak was determined using an incremental workload test on an electromagnetic brake cycle (SECA 545: Volga and Holke, Hamburg, Germany). Volunteers began pedalling at a comfortable rate at a workload of $20 \mathrm{~W}$. They were asked to continue cycling at the same rate and the workload was increased by $20 \mathrm{~W}$ every $2 \mathrm{~min}$ until they had exercised for $10 \mathrm{~min}$. The workload was then increased by $20 \mathrm{~W}$ every $1 \mathrm{~min}$. Volunteers were asked to continue until the respiratory quotient was $>1.1$ and they had reached $90 \%$ of their target heart rate as described above. Cardiorespiratory fitness as measured by $\mathrm{VO}_{2}$ peak was corrected for total body weight.

Physical activity energy expenditure PAEE was assessed using heart rate monitoring (HRFlex method) and the Baecke physical activity questionnaire [18]. The HRFlex method uses an individual calibration of the relationship between energy expenditure and heart rate on exertion, together with measurement of resting energy expenditure and estimation of heart rate at which the linear assumption does not hold (at low energy expenditure) the 'flex' point [19]. This Flex heart rate is taken empirically as the mean of the highest pulse rate at rest and the lowest pulse rate during exercise. The HRFlex method has been compared in validation studies with the 'gold standard' techniques of doubly labelled water (for references see [20]), which suggests that the technique provides an accurate estimate of energy expenditure with a mean error for estimating total energy expenditure of as little as $0.6 \%$. 
Volunteers were asked to wear a heart rate monitor Polar Instruments, Lake Success, NY, USA (for all waking hours on three typical days, usually two weekdays and a weekend day. Volunteers were shown how to fit the chest electrodes and transmitter with a recording device worn on the wrist. They were asked to wear the monitor from after washing in the morning until they went to bed at night. The monitor recorded heart rate every $15 \mathrm{~s}$ and the data were downloaded using infrared software. The readings were analysed after a manual check on each file and exclusion of all heart rate readings of zero beats per min and greater than 200 beats per min. PAEE over 3 days was calculated using the individual relationship between heart rate and average $\mathrm{VO}_{2}$ for each workload. This relationship was then used to calculate average daily PAEE for all free-living heart rate readings that were greater than the lowest heart rate during light exercise; these were then averaged over the 3 day period. Data on free-living PAEE are expressed in relation to body weight (i.e. $\mathrm{kJ} \mathrm{kg}^{-1}$ day $^{-1}$ ). Please note that the PAEE heart rate monitoring data were incomplete for four volunteers (one volunteer, despite our best efforts, failed to return the heart rate monitor; three others did not have suitable heart rate data from the treadmill test to calculate the flex point).

Baecke's questionnaire, which was also used to assess PAEE, includes 16 questions, focusing on a composite score for three components of physical activity in the last 12 months: (1) occupational physical activity (eight questions); (2) physical activity in leisure (four questions); and (3) leisure and locomotion physical activities (four questions). A simple formula is used that takes account of the intensity of the activity, the amount of time spent undertaking the activity and the proportion of time annually spent undertaking the activity.

Vigorous physical activity Using the data from the heart rate monitoring, the amount of time per day spent at over twice the resting heart rate $(2 \times$ heart rate) was calculated as a measure of time spent in vigorous physical activity. This estimate of vigorous physical activity corresponded to approximately $61 \%$ of $\mathrm{VO}_{2}$ peak in this group of men and is significantly correlated with time spent engaged in vigorous physical activity as measured by accelerometry in healthy but overweight adults $(r=0.46, p<0.01$; U. Ekelund, N. Wareham, unpublished results).

Measurement of insulin sensitivity Whole-body and liver insulin sensitivity were measured during the hyperinsulinaemic-euglycaemic clamp. An initial insulin infusion rate of $1.5 \mathrm{mU} \mathrm{kg}^{-1} \min ^{-1}$ was used. Insulin sensitivity was measured as glucose infusion during the steady state of the clamp, when insulin levels were constant. All individuals achieved euglycaemia during the clamp with glucose concentrations clamped between 4.5 and $5.0 \mathrm{mmol} / \mathrm{l}$. Steady-state insulin concentrations were achieved for all individuals during the last $30 \mathrm{~min}$ of the clamp when the $M$ value (whole-body insulin sensitivity) was estimated. There was little variation in insulin concentration between individuals during the steady-state period (mean \pm SD: $168 \pm$ $40 \mathrm{pmol} / \mathrm{l})$. An infusion of deuterated glucose was given at the same time to estimate hepatic insulin sensitivity measured by insulin-mediated suppression of endogenous glucose production [21, 22]. Deuterium-labelled glucose was used as a steady-state infusion for $150 \mathrm{~min}$ prior to commencing the insulin infusion and was continued throughout the clamp. Whole-body insulin sensitivity ( $M$ value) was defined as the glucose infusion rate during the final $30 \mathrm{~min}$ of the test in $\mathrm{mg} \mathrm{kg}^{-1} \mathrm{~min}^{-1}$.

The total appearance of glucose $\left(R_{\mathrm{a}}\right)$, endogenous glucose production and disappearance of glucose $\left(R_{\mathrm{d}}\right)$ were calculated using a modified version of the equations formulated by Steele $[22,23]$. Tracer to tracee ratios (TTRs) were calculated as the ratio of the two areas from the mass spectrometry data. TTR and plasma glucose values were smoothed using the method of optical segments. For the Steele equations, 65\% was used as the effective fraction and $0.22 \mathrm{l} / \mathrm{kg}$ as the distribution volume of glucose for calculation of $R_{\mathrm{a}}$ and $R_{\mathrm{d}}$ [22, 24]. Hepatic insulin sensitivity was measured as insulin-mediated suppression of glucose output in the early part of the clamp and was expressed as percentage suppression $60 \mathrm{~min}$ after commencing the insulin infusion, when suppression was linear to this time point $[25,26]$.

NEFA were measured in the fasting state and during the OGTT to allow measurement of insulin-mediated suppression of NEFA concentration [25, 27, 28]. NEFA concentrations were measured in heparinised plasma samples with an autoanalyser (Konelab 20; Thermo Electon, Waltham, MA, USA). The insulin sensitivity index (ISI) for NEFA was estimated using data from fasting, 1 and $2 \mathrm{~h}$ samples for insulin and NEFA concentrations, according to the method for calculating insulin sensitivity in fat from data obtained during an OGTT [27].

Statistical analyses All statistical analyses were performed using SPSS for Windows version 14.0 (SPSS, Chicago, IL, USA). Student's $t$ test comparisons were undertaken to compare mean values of normally distributed data. Pearson correlation coefficients are presented for univariate regression analyses of normally distributed data. Where variables were not normally distributed, log transformation was undertaken to normalise the distribution. Multivariate linear regression modelling was done to describe factors that were independently associated with insulin sensitivity (wholebody, liver and fat) as the dependent (outcome) variable. The outcomes were whole-body insulin sensitivity or 
insulin sensitivity in individual tissues (liver and fat). A $p$ value of $<0.05$ was considered to be statistically significant for all analyses.

\section{Results}

Main findings Baseline characteristics of the men are shown in Table 1.

Univariate associations for relationships between fatness, fitness, physical activity and insulin sensitivity (wholebody, liver and fat) are shown in Table 2. Relationships between fatness and insulin sensitivity were strong and similar both for total fat and for truncal fat.

Fitness, as measured by $V \mathrm{O}_{2}$ peak, correlated with whole-body insulin sensitivity ( $M$ value; $r=0.53, p=0.007$ ) and also with the individual measures of tissue insulin sensitivity for liver (suppression of endogenous glucose output) and for fat (ISI NEFA). PAEE was positively associated with liver insulin sensitivity $(r=0.55, p=0.01$; Table 2).

Regression models with insulin sensitivity (whole-body, liver or fat) as the outcome Linear regression analysis was undertaken to estimate the relative contribution of fatness, fitness and PAEE to insulin sensitivity. Three regression models were generated (Tables 3, 4 and 5) to study factors associated with insulin sensitivity (wholebody, liver and fat) as the outcome. The explanatory variables included in each of these models were: PAEE, $V \mathrm{O}_{2}$ peak, total fat and the two remaining insulin sensitivity measures, included according to the outcome insulin sensitivity measure. For example, if wholebody insulin sensitivity was the outcome, then fat and liver insulin sensitivity measures were included as explanatory variables. Please note: results shown in Tables 3, 4 and 5 include total fat as an explanatory variable, but remarkably similar models were generated by replacing total fat by truncal fat as an explanatory variable. In a model containing whole-body insulin sensitivity as the outcome (Table 3), only total fatness was strongly and independently associated with the outcome ( $p=0.001$ ) and the $R^{2}$ for this model was 0.86 . These analyses were repeated after excluding the volunteers whose fitness was assessed using the cycle, with very similar results. To further explore the contribution of fitness and physical activity to whole-body insulin sensitivity, the adjusted $R^{2}$ for the model was estimated in stepwise linear regression. In a model excluding fitness and physical activity, the $R^{2}$ was 0.65 , indicating that fatness (total) explains a large percentage $(65 \%)$ of the variation in wholebody insulin sensitivity.

These analyses were repeated with either insulin sensitivity in fat or liver as the outcome of interest. For ISI NEFA, no factors were independently associated with the outcome (Table 5). However if whole-body insulin sensitivity were omitted from this model, fatness became independently associated with ISI NEFA $(p=0.004)$. For liver insulin sensitivity (suppression of endogenous glucose output), by contrast, we noted marked differences in associations of PAEE, fitness and fatness with the outcome. Strong associations were noted only between PAEE and liver insulin sensitivity, this association being independent

Table 2 Relationships between insulin sensitivity (whole-body, fat and liver) and fatness, fitness and physical activity energy expenditure

\begin{tabular}{|c|c|c|c|c|c|c|c|c|}
\hline & & $\begin{array}{l}\text { Total fat } \\
(\mathrm{g})\end{array}$ & $\begin{array}{l}\text { Truncal fat } \\
(\mathrm{g})\end{array}$ & 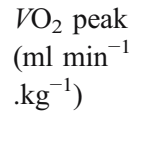 & $\begin{array}{l}\text { PAEE } \\
\left(\mathrm{kJ} \mathrm{kg}^{-1}\right. \\
\left.. \text { day }^{-1}\right)\end{array}$ & $\begin{array}{l}M \text { value } \\
\left(\mathrm{mg} \mathrm{kg}^{-1}\right. \\
\left.\min ^{-1}\right)\end{array}$ & $\begin{array}{l}\text { ISI NEFA } \\
\text { index }\end{array}$ & $\begin{array}{l}\text { Suppression } \\
\text { hepatic } \\
\text { glucose } \\
\text { output (\%) }\end{array}$ \\
\hline Total fat $(\mathrm{g})$ & $\begin{array}{l}r \text { value } \\
p \text { value }\end{array}$ & 1 & & & & & & \\
\hline Truncal fat $(\mathrm{g})$ & $\begin{array}{l}r \text { value } \\
p \text { value }\end{array}$ & $\begin{aligned} & 0.99 \\
< & 0.0005\end{aligned}$ & 1 & & & & & \\
\hline$V \mathrm{O}_{2}$ peak $\left(\mathrm{ml} \mathrm{min}{ }^{-1} \mathrm{~kg}^{-1}\right)$ & $\begin{array}{l}r \text { value } \\
p \text { value }\end{array}$ & $\begin{array}{l}-0.57 \\
0.003\end{array}$ & $\begin{array}{l}-0.54 \\
0.003\end{array}$ & 1 & & & & \\
\hline PAEE $\left(\mathrm{kJ} \mathrm{kg}^{-1} \text { day }^{-1}\right)^{\mathrm{a}}$ & $\begin{array}{l}r \text { value } \\
p \text { value }\end{array}$ & $\begin{array}{c}-0.45 \\
0.04\end{array}$ & $\begin{array}{c}-0.47 \\
0.03\end{array}$ & $\begin{array}{l}0.11 \\
0.65\end{array}$ & 1 & & & \\
\hline$M$ value $\left(\mathrm{mg} \mathrm{kg}^{-1} \min ^{-1}\right)$ & $\begin{array}{l}r \text { value } \\
p \text { value }\end{array}$ & $\begin{array}{c}-0.80 \\
<0.0005\end{array}$ & $\begin{array}{c}-0.81 \\
<0.0005\end{array}$ & $\begin{array}{c}0.53 \\
0.007\end{array}$ & $\begin{array}{l}0.17 \\
0.46\end{array}$ & 1 & & \\
\hline ISI NEFA & $\begin{array}{l}r \text { value } \\
p \text { value }\end{array}$ & $\begin{array}{c}-0.63 \\
<0.001\end{array}$ & $\begin{array}{l}-0.67 \\
<0.001\end{array}$ & $\begin{array}{l}0.38 \\
0.06\end{array}$ & $\begin{array}{c}-0.02 \\
0.92\end{array}$ & $\begin{array}{c}0.74 \\
<0.001\end{array}$ & 1 & \\
\hline Suppression hepatic glucose output (\%) & $\begin{array}{l}r \text { value } \\
p \text { value }\end{array}$ & $\begin{array}{l}-0.53 \\
0.003\end{array}$ & $\begin{array}{l}-0.54 \\
0.002\end{array}$ & $\begin{array}{l}0.42 \\
0.04\end{array}$ & $\begin{array}{l}0.55 \\
0.01\end{array}$ & $\begin{array}{c}0.56 \\
0.002\end{array}$ & $\begin{array}{l}0.34 \\
0.07\end{array}$ & 1 \\
\hline
\end{tabular}

${ }^{\mathrm{a}} n=21$ subjects (PAEE data not available on four men) 
Table 3 Regression model with whole-body insulin sensitivity ( $M$ value) as the outcome variable and total fat, fitness and physical activity energy expenditure as explanatory variables

\begin{tabular}{llll}
\hline & $\begin{array}{l}\text { Unstandardised } \\
B \text { coefficient }\end{array}$ & $\begin{array}{l}95 \% \\
\text { CIs }\end{array}$ & $p$ value \\
\hline $\begin{array}{l}\text { Liver insulin sensitivity } \\
\text { (\% suppression) }\end{array}$ & 0.002 & $0.0,0.01$ & 0.07 \\
$\begin{array}{l}\text { Fat ISI } \\
V \mathrm{O}_{2} \text { peak }\end{array}$ & -0.20 & $-0.05,0.01$ & 0.10 \\
$\left(\mathrm{ml} \mathrm{min} \mathrm{kg}^{-1}\right)$ & 0.11 & $-0.54,0.33$ & 0.61 \\
PAEE $\left(\mathrm{kJ} \mathrm{kg}^{-1} \mathrm{day}^{-1}\right)^{\mathrm{a}}$ & -0.05 & $-0.11,0.04$ & 0.07 \\
Total fat $\left(\mathrm{kg}^{2}\right.$ & -0.01 & $0.0,0.01$ & 0.001 \\
\hline
\end{tabular}

Model summary, $R^{2}=0.86$; residual SD of the model, 0.08

${ }^{a} n=21$ volunteers (PAEE data not available on four men)

of fatness (truncal or total) and fitness (results for model including total fat, see Table 4). This model explained $60 \%$ of the variance in liver insulin sensitivity $\left(R^{2}=0.6\right)$.

To further explore the relationship between the intensity of physical activity and liver insulin sensitivity, we examined the relationships between the derived measures of more intense physical activity (Baecke sport and time spent with a heart rate $>2 \times$ resting heart rate, see "Materials and methods") and liver insulin sensitivity in the multiple regression modelling. Replacing PAEE with Baecke sport (in the regression model shown in Table 4), the results were very similar and supported the data shown in Table 4, with only Baecke sport being independently associated with liver insulin sensitivity $(B$ coefficient $=11.40,95 \% \mathrm{CI} 2.75-$ 20.05, $p=0.012$ ). The results were similar, if PAEE was replaced in the regression model shown in Table 4 by the measure of intense physical activity from the heart rate monitoring data, i.e. amount of time spent with a heart rate

Table 4 Regression model with hepatic insulin sensitivity as the outcome variable and total fat, fitness and physical activity energy expenditure as explanatory variables

\begin{tabular}{llll}
\hline & $\begin{array}{l}\text { Unstandardised } \\
B \text { coefficient }\end{array}$ & $\begin{array}{l}95 \% \\
\mathrm{CIs}\end{array}$ & $p$ value \\
\hline $\begin{array}{l}\text { Whole-body insulin } \\
\text { sensitivity (mg } \\
\left.\mathrm{kg}^{-1} \mathrm{~min}^{-1}\right)\end{array}$ & 90.8 & $-9.0,190.6$ & 0.07 \\
$\begin{array}{l}\text { Fat ISI } \\
V \mathrm{O}_{2} \text { peak (ml }\end{array}$ & -9.4 & & \\
$\left.\mathrm{~min}^{-1} \mathrm{~kg}^{-1}\right)$ & 46.0 & $-62.5,43.7$ & 0.71 \\
PAEE $\left(\mathrm{kJ} \mathrm{kg}^{-1} \text { day }^{-1}\right)^{\mathrm{a}}$ & 13.5 & $-38.6,130.5$ & 0.27 \\
Total fat $\left(\mathrm{kg}^{2}\right.$ & 1.0 & $2.5,24.5$ & 0.02 \\
\hline
\end{tabular}

Hepatic insulin sensitivity expressed as the \% glucose suppression during the first $60 \mathrm{~min}$ of the hyperinsulinaemic clamp. Model summary, $R^{2}=0.6$; residual SD of the model, 16.6

${ }^{\mathrm{a}} n=21$ volunteers (PAEE data not available on four men)
Table 5 Regression model with fat insulin sensitivity as the outcome variable and total fat, fitness and physical activity energy expenditure as explanatory variables

\begin{tabular}{llll}
\hline & $\begin{array}{l}\text { Unstandardised } \\
B \text { coefficient }\end{array}$ & $\begin{array}{l}95 \% \\
\text { CIs }\end{array}$ & $p$ value \\
\hline $\begin{array}{l}\text { Whole-body insulin } \\
\text { sensitivity (mg kg } \\
\left.\text { min }^{-1}\right)\end{array}$ & 0.85 & $-0.20,1.91$ & 0.10 \\
$\begin{array}{l}\text { Liver insulin sensitivity } \\
(\% \text { suppression) }\end{array}$ & -0.001 & $-0.01,0.01$ & 0.71 \\
$\begin{array}{l}V \mathrm{O}_{2} \text { peak (ml } \\
\left.\text { min }^{-1} \mathrm{~kg}^{-1}\right)\end{array}$ & 0.20 & $-0.71,1.11$ & 0.65 \\
${\mathrm{PAEE}\left(\mathrm{kJ} \mathrm{kg}^{-1} \text { day }^{-1}\right)^{\mathrm{a}}}_{\text {Total fat }(\mathrm{kg})}$ & -0.04 & $-0.18,0.10$ & 0.50 \\
\hline
\end{tabular}

Model summary, $R^{2}=0.64$; residual SD of the model, 0.17

${ }^{\mathrm{a}} n=21$ volunteers (PAEE data not available on four men)

$>2 \times$ resting heart rate (see "Materials and methods"; $B$ coefficient $=0.85,95 \% \mathrm{CI} 0.10-1.60, p=0.028)$.

\section{Discussion}

It is well established that measures of fatness are strongly associated with insulin sensitivity in univariate analyses. Here we have confirmed that fatness is strongly and independently associated with whole-body insulin sensitivity. At the same time we have shown for the first time that the relationship between fatness and liver insulin sensitivity is not independent of PAEE and fitness. Moreover, in a regression model with liver insulin sensitivity as the outcome and a measure of fatness, PAEE and fitness as explanatory variables, only PAEE was independently associated with the outcome. This model explained $60 \%$ of the variance in liver insulin sensitivity. In exploring which component of physical activity is most important in influencing liver insulin sensitivity, we have also shown that the time spent undertaking more intense physical activity, as measured both by questionnaire and heart rate monitoring, was strongly associated with liver insulin sensitivity.

Interpreting these findings, the measure of whole-body insulin sensitivity ( $M$ value) is largely influenced by insulin-mediated glucose disposal into skeletal muscle, while both measures of fatness (total and truncal) were very strongly associated with $M$ value. In contrast, the associations between $M$ value and physical activity or fitness were weaker. Thus these data suggest that much of the impact of physical activity and fitness on muscle (and whole-body) insulin sensitivity is likely to be mediated via an effect of physical activity and fitness that leads to a decrease in body fat. Fitness alone only explained an 
additional 2 to $3 \%$ of the variance in whole-body insulin sensitivity in addition to the $65 \%$ explained by fatness.

The mechanisms by which physical activity may improve insulin sensitivity have recently been reviewed [29-32]. Increased regular physical activity may increase skeletal muscle fat oxidative capacity, thereby decreasing the available fatty acid supply to the liver. It is plausible that the more prolonged and vigorous the activity, the greater the capacity for skeletal muscle oxidation. In support of our findings showing an independent association of PAEE, and in particular the more intense component of PAEE, with liver insulin sensitivity, the effect of an exercise intervention on tissue insulin sensitivity has recently been studied in middle-aged individuals [11]. In that study, volunteers randomised to the exercise arm of the trial exercised at 60 to $85 \%$ of maximal aerobic capacity $\left(\mathrm{VO}_{2}\right.$ peak), for a minimum of three times each week for 6 weeks. Exercise was shown to produce an improvement in liver insulin sensitivity that was not attributable to the acute benefit of physical activity. Moreover, exercise did not change total fat mass, whereas an improvement in fitness was seen. These published data and the present results support the notion that there is an effect of physical activity on liver insulin sensitivity that is independent of fat mass. The mechanism underlying such an association may be mediated by a decrease, effected by physical activity, in plasma NEFA concentrations [11]. Increased NEFA supply to the liver may directly cause liver insulin resistance, as acutely increasing plasma NEFA concentrations, as previously shown, worsens hepatic insulin sensitivity [33]. Recently published data support the notion of the importance of physical activity in regulating insulin sensitivity specifically in liver, independently of any influence of heredity [34]. The investigators studied the heredityindependent effects of physical activity and fitness on NEFA uptake in skeletal muscle and liver. The volunteers were young male monozygotic twin pairs, discordant for physical activity and fitness. The co-twins with higher physical activity levels, constituted the more active group. At rest the more active group had lower liver NEFA uptake than the less active group; interestingly there was no difference in skeletal muscle uptake between both groups.

Both low fitness and high fatness have been demonstrated to increase overall and cardiovascular mortality to a similar degree, but it remains unclear to what extent these risks are independent of one another [35-38]. It has been suggested that low fitness is largely responsible for the increased mortality risk associated with obesity. However, a recent review of the literature emphasises the lack of evidence that improved fitness improves the metabolic profile in the absence of any weight loss [39]. Interventional studies that improve fitness have shown benefit to cardiovascular risk factors, but these interventions have also resulted in improvements in body composition [40, 41]. Furthermore, regression analyses have shown that improvements in body composition were responsible for the increase in insulin sensitivity, rather than improved fitness [41]. Physical training decreases visceral and subcutaneous fat mass when combined with dietary restriction, with no difference between aerobic exercise and resistance exercise [42]. We have demonstrated an inverse relationship between fitness and fatness, and between energy expenditure and fatness, although interestingly we did not demonstrate any relationship between physical activity or fitness and visceral fat as measured by magnetic resonance imaging in a subgroup of 19 individuals (data not shown). Because our magnetic resonance imaging data were incomplete, we are unable to comment with certainty on the precise relationship between physical activity and visceral, subcutaneous or liver fat. Our volunteers were middle-aged men who were not athletes, and the question of whether intense and prolonged exercise is needed to influence visceral fat levels still needs to be determined.

The strengths of our study are that we measured total and truncal body fatness, and tissue insulin sensitivity in liver and fat, as well as measuring whole-body insulin sensitivity. In addition we measured fitness by $\mathrm{VO}_{2}$ peak, rather than by a submaximal test, and physical activity (by heart rate monitoring and Baecke questionnaire). The measure of whole-body insulin sensitivity ( $M$ value) estimates whole-body glucose uptake, although most of this measure reflects skeletal muscle glucose uptake during the hyperinsulinaemic clamp. The measure of hepatic insulin sensitivity that we derived from $R_{\mathrm{a}}$ reflects wholebody endogenous glucose production during the early part of the hyperinsulinaemic clamp. We derived this measure from the data obtained during the early phase of the clamp, when glucose suppression was linear $[25,26]$, because at the end of the clamp hepatic glucose output was completely suppressed in all individuals and therefore did not allow discrimination of liver insulin sensitivity between individuals. Unfortunately, it was not possible in these volunteers to also undertake a low-dose insulin clamp to assess suppression of hepatic glucose output.

In summary we have found that only fatness is independently associated with whole-body insulin sensitivity after adjusting for fitness and physical activity. In contrast, we show that only PAEE is independently associated with liver insulin sensitivity and neither fatness nor fitness is independently associated with this outcome. These results suggest there may be a differential impact of physical activity, fatness and fitness on individual tissue insulin sensitivity. Further interventional studies are now needed to investigate the impact of different forms and intensities of physical activity and exercise on individual insulin-sensitive tissues. 
Acknowledgements We would like to thank the staff of the Wellcome Trust Clinical Research Facility for their help with this study. We would like to thank L. England for her help with this manuscript and N. Englyst and A. Ward for their advice. The work was funded by grant support from the Wellcome Trust to C. Byrne and by support from Wessex Deanery and from NHS Research and Development funding.

Duality of interest There were no conflicts of interest.

\section{References}

1. Gill JM (2007) Physical activity, cardiorespiratory fitness and insulin resistance: a short update. Curr Opin Lipidol 18:47-52

2. Mayer-Davis EJ, D'Agostino R Jr, Karter AJ et al (1998) Intensity and amount of physical activity in relation to insulin sensitivity: the insulin resistance atherosclerosis study. JAMA 279:669-674

3. Gill JM, Malkova D (2006) Physical activity, fitness and cardiovascular disease risk in adults: interactions with insulin resistance and obesity. Clin Sci (Lond) 110:409-425

4. Carroll S, Cooke CB, Butterly RJ (2000) Metabolic clustering, physical activity and fitness in nonsmoking, middle-aged men. Med Sci Sports Exerc 32:2079-2086

5. Whaley MH, Kampert JB, Kohl HW III, Blair SN (1999) Physical fitness and clustering of risk factors associated with the metabolic syndrome. Med Sci Sports Exerc 31:287-293

6. Kasa-Vubu JZ, Lee CC, Rosenthal A, Singer K, Halter JB (2005) Cardiovascular fitness and exercise as determinants of insulin resistance in postpubertal adolescent females. J Clin Endocrinol Metab 90:849-854

7. LaMonte MJ, Blair SN, Church TS (2005) Physical activity and diabetes prevention. J Appl Physiol 99:1205-1213

8. Nassis GP, Papantakou K, Skenderi K et al (2005) Aerobic exercise training improves insulin sensitivity without changes in body weight, body fat, adiponectin, and inflammatory markers in overweight and obese girls. Metabolism 54:1472-1479

9. Lee S, Kuk JL, Katzmarzyk PT, Blair SN, Church TS, Ross R (2005) Cardiorespiratory fitness attenuates metabolic risk independent of abdominal subcutaneous and visceral fat in men. Diabetes Care 28:895-901

10. Ekelund U, Griffin SJ, Wareham NJ (2007) Physical activity and metabolic risk in individuals with a family history of type 2 diabetes. Diabetes Care 30:337-342

11. Shojaee-Moradie F, Baynes KC, Pentecost C et al (2007) Exercise training reduces fatty acid availability and improves the insulin sensitivity of glucose metabolism. Diabetologia 50:404-413

12. Borghouts LB, Keizer HA (2000) Exercise and insulin sensitivity: a review. Int J Sports Med 21:1-12

13. Houmard JA, Tanner CJ, Slentz CA, Duscha BD, McCartney JS, Kraus WE (2004) Effect of the volume and intensity of exercise training on insulin sensitivity. J Appl Physiol 96:101106

14. Ross R, Dagnone D, Jones PJ et al (2000) Reduction in obesity and related comorbid conditions after diet-induced weight loss or exercise-induced weight loss in men. A randomized, controlled trial. Ann Intern Med 133:92-103

15. Wareham NJ, Hennings SJ, Byrne CD, Hales CN, Prentice AM, Day NE (1998) A quantitative analysis of the relationship between habitual energy expenditure, fitness and the metabolic cardiovascular syndrome. Br J Nutr 80:235-241
16. Knowler WC, Barrett-Connor E, Fowler SE et al (2002) Reduction in the incidence of type 2 diabetes with lifestyle intervention or metformin. N Engl J Med 346:393-403

17. Hamman RF, Wing RR, Edelstein SL et al (2006) Effect of weight loss with lifestyle intervention on risk of diabetes. Diabetes Care 29:2102-2107

18. Baecke JAH, Burema J, Frijters JER (1982) A short questionnaire for the measurement of habitual physical activity in epidemiological studies. Am J Clin Nutr 36:936-942

19. Leonard WR (2003) Measuring human energy expenditure: what have we learned from the flex-heart rate method? Am J Human Biol 15:479-489

20. Wareham NJ, Hennings SJ, Prentice AM, Day NE (1997) Feasibility of heart-rate monitoring to estimate total level and pattern of energy expenditure in a population-based epidemiological study: the Ely Young cohort feasibility study 1994-5. Br J Nutr 78:889-900

21. DeFronzo RA, Tobin JD, Andres R (1979) Glucose clamp technique: a method for quantifying insulin secretion and resistance. Am J Physiol 237:E214-E223

22. Powrie JK, Smith GD, Hennessy TR et al (1992) Incomplete suppression of hepatic glucose production in non-insulin dependent diabetes mellitus measured with $\left[6,6-{ }^{2} \mathrm{H}_{2}\right]$ glucose enriched glucose infusion during hyperinsulinaemic euglycaemic clamps. Eur J Clin Investig 22:244-253

23. Steele R (1959) Influences of glucose loading and of injected insulin on hepatic glucose output. Ann N Y Acad Sci 82:420 430

24. Finegood DT, Bergman RN (1983) Optimal segments: a method for smoothing tracer data to calculate metabolic fluxes. Am J Physiol 244:E472-E479

25. Holt HB, Wild SH, Wood PJ et al (2006) Non-esterified fatty acid concentrations are independently associated with hepatic steatosis in obese subjects. Diabetologia 49:141-148

26. Holt HB, Wild SH, Postle AD et al (2007) Cortisol clearance and associations with insulin sensitivity, body fat and fatty liver in middle-aged men. Diabetologia 50:1024-1032

27. Belfiore F, Iannello S, Volpicelli G (1998) Insulin sensitivity indices calculated from basal and OGTT-induced insulin, glucose, and FFA levels. Mol Genet Metab 63:134-141

28. Byrne CD, Wareham NJ, Day NE, McLeish R, Williams DR, Hales CN (1995) Decreased non-esterified fatty acid suppression and features of the insulin resistance syndrome occur in a subgroup of individuals with normal glucose tolerance. Diabetologia 38:1358-1366

29. Wojtaszewski JF, Jorgensen SB, Frosig C, MacDonald C, Birk JB, Richter EA (2003) Insulin signalling: effects of prior exercise. Acta Physiol Scand 178:321-328

30. Zierath JR (2002) Invited review: exercise training-induced changes in insulin signaling in skeletal muscle. J Appl Physiol 93:773-781

31. Holloszy JO (2005) Exercise-induced increase in muscle insulin sensitivity. J Appl Physiol 99:338-343

32. Christ-Roberts CY, Mandarino LJ (2004) Glycogen synthase: key effect of exercise on insulin action. Exerc Sport Sci Rev 32:90-94

33. Bevilacqua S, Bonadonna R, Buzzigoli G et al (1987) Acute elevation of free fatty acid levels leads to hepatic insulin resistance in obese subjects. Metabolism 36:502-506

34. Hannukainen JC, Nuutila P, Ronald B et al (2007) Increased physical activity decreases hepatic free fatty acid uptake: a study in human monozygotic twins. J Physiol 578:347-358

35. Katzmarzyk PT, Church TS, Janssen I, Ross R, Blair SN (2005) Metabolic syndrome, obesity, and mortality: impact of cardiorespiratory fitness. Diabetes Care 28:391-397 
36. Wei M, Kampert JB, Barlow CE et al (1999) Relationship between low cardiorespiratory fitness and mortality in normal-weight, overweight, and obese men. JAMA 282:1547-1553

37. Wei M, Gibbons LW, Kampert JB, Nichaman MZ, Blair SN (2000) Low cardiorespiratory fitness and physical inactivity as predictors of mortality in men with type 2 diabetes. Ann Intern Med 132:605-611

38. Jonsson S, Hedblad B, Engstrom G, Nilsson P, Berglund G, Janzon L (2002) Influence of obesity on cardiovascular risk. Twenty-three-year follow-up of 22,025 men from an urban Swedish population. Int J Obes Relat Metab Disord 26:10461053
39. Carroll S, Dudfield M (2004) What is the relationship between exercise and metabolic abnormalities? A review of the metabolic syndrome. Sports Med 34:371-418

40. Stewart KJ, Bacher AC, Turner K et al (2005) Exercise and risk factors associated with metabolic syndrome in older adults. Am J Prev Med 28:9-18

41. Walker KZ, Piers LS, Putt RS, Jones JA, O’Dea K (1999) Effects of regular walking on cardiovascular risk factors and body composition in normoglycemic women and women with type 2 diabetes. Diabetes Care 22:555-561

42. Ross R, Rissanen J, Pedwell H, Clifford J, Shragge P (1996) Influence of diet and exercise on skeletal muscle and visceral adipose tissue in men. J Appl Physiol 81:2445-2455 